\title{
UNDERSTANDING CHANGE PROCESS AND ORGANISATIONAL PERFORMANCE ASSOCIATED WITH ENTERPRISE SYSTEM IMPLEMENTATION
}

\author{
Wallayaporn Techakriengkrai \\ ICL Graduate Business School, New Zealand
}

\begin{abstract}
The enterprise system implementation process is considered to be a complex process that impacts organisations, processes, tasks, knowledge and skills, and relationships with clients and suppliers. Organisations that implement an enterprise system are required to make changes in their business, modify their business processes, and restructure their organisations to obtain the benefits of the new system. Past research on enterprise system has largely focused on organisational initial adoption decisions on an enterprise system. However, there has been little research concerning the continued use of an enterprise system and the associated change process in the post-adoption stage. Therefore, this proposed research will attempt to fill the gap in knowledge by examining the post-adoptive change and organisational performance resulting from organisational enterprise system implementation. The research questions are: (1) How do organisational changes unfold in enterprise system implementation? (2) How do enterprise systems shape organisational performance in the post-adoption stage of enterprise system implementation? This research will adopt the qualitative interpretive case study method to examine the change process and organisational change associated with enterprise system implementation in organisations. This study will employ the embedded multiple-case design. Semi-structured interviews will be conducted in this study. The proposed research will develop new knowledge based on how an integrated theoretical perspective using institutional logics and a socio-technical perspective can inform changes in organisations. The findings will assist organisations in providing appropriate resources and support for successful enterprise system implementation in the post-adoption stage.
\end{abstract}

\section{KEYWORDS}

Post-Adoption, Enterprise System Implementation, Organisational Change, Organisational Performance, Socio-Technical Perspective, Institutional Logics

\section{INTRODUCTION}

This proposed research will focus on enterprise system implementation. Enterprise systems are commercial software packages that include Enterprise Resource Planning (ERP), Customer Relationship Management (CRM), Supply Chain Management (SCM), and others (Markus \& Tanis, 1999). The enterprise system implementation process is considered to be a complex process that impacts organisations, processes, tasks, knowledge and skills, and relationships with clients and suppliers (Wognum et al., 2004). Organisations that implement an enterprise system are required to make changes in their business, modify their business processes, and restructure their organisations to obtain the benefits of the new system (Davenport, 1998). Past research on enterprise system has largely focused on organisational initial adoption decisions on an enterprise system. However, there has been little research concerning the continued use of an enterprise system and the associated change process in the post-adoption stage (See et al., 2019). At the post-adoption stage, individuals commence using the enterprise system to support and accomplish work tasks. In this study, post-adoptive behaviour is regarded as that which occurs after the enterprise system has been installed in the organisations. There are continuous adjustments and improvisations in IS use. In other words, users can adapt and change their behaviours in IS use (Sun, 2012). Therefore, this proposed research will attempt to fill the gap in knowledge by examining the post-adoptive changes resulting from organisational enterprise system implementation. CRM and ERP systems are considered as particular types of an enterprise system. CRM implementation has shown to have a $63 \%$ fail rate based on a survey in the US by Merkle Group Inc (2018), while ERP implementation has had a $75 \%$ fail rate (Gartner, 2018). These failures can potentially be 
attributed to organisations tending to focus on the system itself without being concerning with the issues of integrating culture, processes, people, and technology within and across the organisational context (Finnegan \& Carrie, 2010). It is argued that technical issues are not the most important issues in enterprise system implementation (Finnegan \& Willcocks, 2007). The main issues of enterprise system implementation are related to organisational change and disruption, changes in the business (Schwartz, 2002), and technology misfit (Finnegan \& Willcocks, 2007). Lack of appropriate technology use is one of the failure factors of enterprise system implementation (Zablah, Bellenger, \& Johnston, 2004). Therefore, the enterprise system is an interesting context in which to examine change in the post-adoption stage of enterprise system implementation. From the organisation's perspective, new enterprise system implementation helps to improve efficiency, effectiveness, and employees' job performance in organisations (Davis, 1993). However, the introduction of a new system tends to include disruptive workplace changes (Orlikowski, 2000), requiring changes elsewhere in the organisation. These include changes in work processes, work practices, relationships between different professional work groups, roles, skills, capacities of the system users (Clegg \& Shepherd, 2007), and balance of identities (Schilhavy \& Iyer, 2007). This study will focus on change process associated with the disruptive change of implementing a new enterprise system in an organisation.

\section{THEORETICAL BACKGROUND AND FOUNDATION}

In this research, the researcher will develop new knowledge based on how an integrated theoretical perspective using institutional logics and a socio-technical perspective can inform changes in organisations. A socio-technical system consists of two subsystems: the social system and the technical system. The social system consists of two components include actor and structure such as culture, norms, skills, and values (Cummings, 1978). The technical system consists of tasks and technology (Kwon \& Zmud, 1987). According to Leavitt (1964), there are four components of a socio-technical system include actors (e.g., project participants and stakeholders) and their characteristics and attributes; tasks which refer to what and how work is accomplished; structure which represents institutionalised rules and arrangements; and technology including hardware, software and tools. Previous IS research that has adopted a socio-technical perspective has allowed researchers to understand change through the interactions of the four socio-technical components after implementing new IS systems, leading to the modification of organisational structures and work processes. A socio-technical perspective is useful to understand an emergent process of change and socio-technical components that affect organisational changes after new enterprise system implementation. Institutional theory can be used as a theoretical lens to "develop a more structural and systemic understanding for how technologies [enterprise systems] are embedded in complex interdependent social, economic, and political networks, and how they are consequently shaped by such broader institutional influences" (Orlikowski \& Barley, 2001). Institutional logics will be used to investigate the interaction between enterprise systems and organisations' structures and processes as well as to identify and explain misalignment problems in enterprise systems implementation (Svejvig, 2009).

\section{RESEARCH OBJECTIVES AND QUESTIONS}

The main objective of this study is to provide a better understanding of the change process in enterprise system implementation and how this change shapes organisational performance. To achieve this, the research explores the change process associated with enterprise system implementation. This research will focus on the post-adoption stage of enterprise system implementation. Specifically, the objectives set out for this study are: (1) To reveal change process in the post-adoption stage of enterprise system implementations and (2) To investigate organisational performance in the post-adoption stage of enterprise system implementations. This proposed study aims to investigate the change process and organisational performance in enterprise system implementation. Institutional theory, and a socio-perspective are used to ground the empirical enquiry on changes in organisations from enterprise system implementation. The main research questions guiding this study are: (1) How do organisational changes unfold in enterprise system implementation? and (2) How do enterprise systems shape organisational performance in the post-adoption stage of enterprise system implementation? 


\section{RESEARCH METHODOLOGY AND APPROACH}

This research will adopt the qualitative interpretive case study method to examine the change process associated with enterprise system implementation in organisations. An interpretive approach is an appropriate approach to develop a rich understanding of the changes and organisational performance associated with new enterprise system implementation in the organisational context. Interpretive case study research aims to understand the nature of phenomena from the point of view of participants and seeks to elicit meanings from behaviour in the social context (Cavaye, 1996). Case study allows researchers to discover an event, an activity, and a process from participants. The case study strategy consists of three main steps: case study design, case study selection, and case study analysis. Case study design involves identifying the unit of analysis, identifying criteria for case selection, determining an appropriate number of cases, selecting an appropriate data collection method, and designing data collection instruments. The case study design involves the decision to use multiple case studies and the preparation of interview questions. This study will employ the embedded multiple-case design (Yin, 2003). A multiple-case design is regarded as more appropriate than a single-case design because a single case approach is suitable for testing the boundaries of well-formed theory or examining an extreme or a unique case. The benefits of adopting a multiple-case design in this study are related to the need to identify a variety of socio-technical changes according to different organisational contexts. Two case studies will be conducted in New Zealand. The unit of analysis is an organisational level. For case study selection, the researcher will adopt a theoretical sampling strategy. Participants will be selected based on their knowledge and expertise in the CRM applications. The last step is case analysis. Within-case and cross-case analysis will be conducted. The researcher will use thematic analysis to analyse data (Braun \& Clarke, 2006). In this study, Nvivo software will be used as a tool to organise and analyse data.

\section{CONCLUSION}

In this research-in-progress paper, the author is in the process of finding appropriate organisations to participate in the study. Two organisations from different industries will be selected to identify a variety of changes and organisational performances according to different organisational contexts. This research will contribute to an understanding of change process in enterprise system implementation. The results will be useful to reveal changes in response to new enterprise system implementation in organisational contexts. In addition, this research will reveal the results in terms of how new enterprise systems shape organisational performance in the post-adoption stage of enterprise system implementation. The proposed research will develop new knowledge based on how an integrated theoretical perspective using institutional logics and a socio-technical perspective can inform changes in organisations. This study will provide practical contributions in several ways. Firstly, the findings will assist organisations in providing appropriate resources and support for successful enterprise system implementation in the post-adoption stage. Secondly, the findings will enable organisations to become aware of unanticipated events and consequences that may occur after enterprise system implementation. Lastly, the results will support IT developers in preparing a good implementation plan for successful implementation.

\section{REFERENCES}

Braun, V. and Clarke, V., 2006. Using thematic analysis in psychology. Qualitative research in psychology, Vol. 3, No. 2, pp 77-101.

Cavaye, A. L., 1996. Case study research: A multi-faceted research approach for IS. Information Systems Journal, Vol. 6 , No. 3, pp 227-242.

Clegg, C. and Shepherd, C., 2007. The biggest computer programme in the world... ever!: Time for a change in mindset? Journal of Information Technology, Vol. 22, No. 3, pp 212-221.

Cummings, T. G., 1978. Self-regulating work groups: A socio-technical synthesis. Academy of Management Review, Vol. 3, No. 3, pp 625-634. doi:10.5465/amr.1978.4305900 
Davenport, T. H., 1998. Putting the enterprise into the enterprise system. Harvard Business Review, Vol. 76, No. 4, pp 1-11.

Davis, F. D., 1993. User acceptance of information technology: System characteristics, user perceptions and behavioral impacts. International journal of Man-Machine Studies, Vol. 38, No. 3, pp 475-487.

Finnegan, D. and Currie, W. L., 2010. A multi-layered approach to CRM implementation: An integration perspective. European Management Journal, Vol. 2, No. 2, pp. 153-167.

Finnegan, D. and Willcocks, L., 2007. Implementing CRM: From technology to knowledge. John Wiley \& Sons, West Sussex, UK.

Gartner, 2018: 75\% of all ERP projects fail - But why? Retrieved from http://officeoffinance.com/gartner-75-of-all-erpprojects-fail-but-why

Kwon, T. H. and Zmud R. W., 1987. Unifying the fragmented models of information systems implementation. In R. J. Boland \& R. A. Hirschheim (Eds.), Critical issues in information sys-tems research (pp. 227-251). John Wiley \& Sons, New York, USA.

Leavitt, H. J., 1964. Applied organization change in industry: Structural, technical and human approaches. New Perspectives in Organizational Research, pp 55-71.

Markus, L. and Tanis, C., 1999. The enterprise systems experience - from adoption to success. In R. W. Zmud (Ed.), Framing the domains of IT research: Glimpsing the future through the past. Pinnaflex Educational Resources, Ohio, USA.

Merkle executive survey, 2018: 7 Must-Know CRM Adoption Statistics and What They Mean for Your CRM. Retrieved from https://www.business2community.com/customer-experience/7-must-know-crm-adoption-statistics-mean-crm02023236

Orlikowski, W. J., 2000. Using technology and constituting structures: A practice lens for studying technology in organizations. Organization Science, Vol. 11, No. 4, pp 404-428.

Orlikowski, W. J. and Barley, S. R., 2001. Technology and institutions: What can research on information technology and research on organizations learn from each other? MIS Quarterly, Vol. 25, No. 2, pp 145-165.

Schilhavy, R. and Iyer, L., 2007. Exploring the information effects of identity and information transparency in reputation systems. Presented at the DIGIT Workshops, Montreal, Canada.

Schwartz, S. J., 2002. In search of mechanisms of change in identity development: Integrating the constructivist and discovery perspectives on identity. International Journal of Theory and Research, Vol. 2, No. 4, pp 317-339.

See, B. P., Yap, C. S. and Ahmad, R., 2019. Antecedents of continued use and extended use of enterprise systems. Behaviour \& Information Technology, Vol. 38, No. 4, pp.384-400.

Sun, H., 2012. Understanding user revisions when using information system features: Adaptive system use and triggers. MIS Quarterly, Vol. 36, No. 2, pp 453-478.

Svejvig, P., 2009. Literature review of enterprise systems research using institutional theory: Towards a conceptual model. Qorking Paper

Wognum, P. et al, 2004. Improving enterprise system support: A case-based approach. Advanced Engineering Informatics, Vol. 18, No. 4, pp 241-253.

Yin, R. K., 2003. Case study research: Design and methods (3rd ed.). Sage Publications, California, USA.

Zablah, A. R. et al., 2004. Customer relationship management implementation gaps. Journal of Personal Selling and Sales Management, Vol. 24, No. 4, pp 279-295. 